\title{
Upward migration of a ureteric stone in a military trainer: a case report
}

\author{
This article was published in the following Dove Press journal: \\ Research and Reports in Urology \\ 19 January 2017 \\ Number of times this article has been viewed
}

\author{
Moayid Fallatah' \\ Sakher Tahaineh ${ }^{2}$ \\ Rawan Abu Mughli ${ }^{3}$ \\ Seddig M Fallatah' \\ 'College of Medicine, Umm Al-Qura \\ University, ${ }^{2}$ Urology Department, \\ ${ }^{3}$ Radiology Department, Security \\ Forces Hospital, Makkah, Saudi Arabia
}

\begin{abstract}
Retrograde ureteric stone migration is an extremely rare phenomenon with only one previously reported case in the literature. We report on a case of upward spontaneous migration of a ureteric stone in a 39-year-old male military trainer in Saudi Arabia who was diagnosed with upper left ureteric stone based on non-contrast spiral computerized tomography kidney ureter bladder (CT-KUB) scan. The plan was to treat the patient conservatively with alpha blockers and oral hydration. Two weeks after treatment started, repeated CT-KUB scan revealed an upward migration of the stone to the left renal calyx. Accordingly, we highly recommend performing a prior stone localizing imaging test to avoid unnecessary procedures or operations.
\end{abstract}

Keywords: ureteric stone, upward migration, reversed peristalsis, excessive exercises

\section{Introduction}

Urolithiasis is considered as one of the most common causatives of admission to the emergency and urology outpatient departments. ${ }^{1}$ Recent studies have shown an increase in the incidence and prevalence of urolithiasis worldwide. ${ }^{2}$ In Saudi Arabia, where our case was reported, the incidence of urolithiasis is $20 \%$, which is considered to be the highest among the regions described in one epidemiological study. ${ }^{3}$

Apart from patients who need either a medical or a surgical intervention to remove their urinary tract stones, a considerable number of patients experience a spontaneous downward movement of their stones out of the body. ${ }^{4,5}$ On the other hand, the upward urinary tract stone migration has been reported only once in the literature. ${ }^{6}$ To the best of our knowledge, we report the second case of retrograde migration of the urinary tract stones.

\section{Case report}

A 39-year-old Pakistani male working as a military trainer presented to our urology clinic on December 2, 2015, complaining of left back pain. The pain started 5 days prior to the visit, and it was severe enough to interfere with his daily activities. There was no hematuria or any other urinary symptoms. The patient was medically and surgically free apart from a previous surgery in his back. The patient denied any history of urolithiasis.

On physical examination, the patient demonstrated left-sided costophrenic angle tenderness.

Therefore, non-contrast spiral computerized tomography kidney ureter bladder (CT-KUB) scan was performed the same day. This showed a $5 \mathrm{~mm}$ left upper ureteric stone with subsequent mild left hydronephrosis (Figure 1). Thereafter, treatment options
Correspondence: Moayid Fallatah College of Medicine, Umm Al-Qura University, Makkah 21955, Saudi Arabia Tel +966595944422

Email Moayidomar@gmail.com 


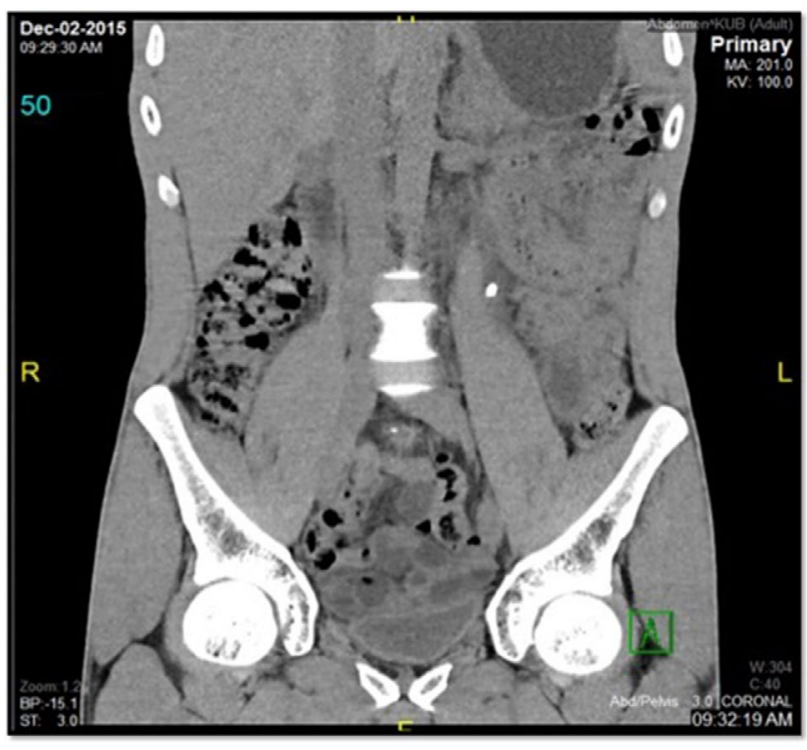

Figure I CT-KUB scan showing the stone location on December 2, 2015. Abbreviation: CT-KUB, computerized tomography kidney ureter bladder.

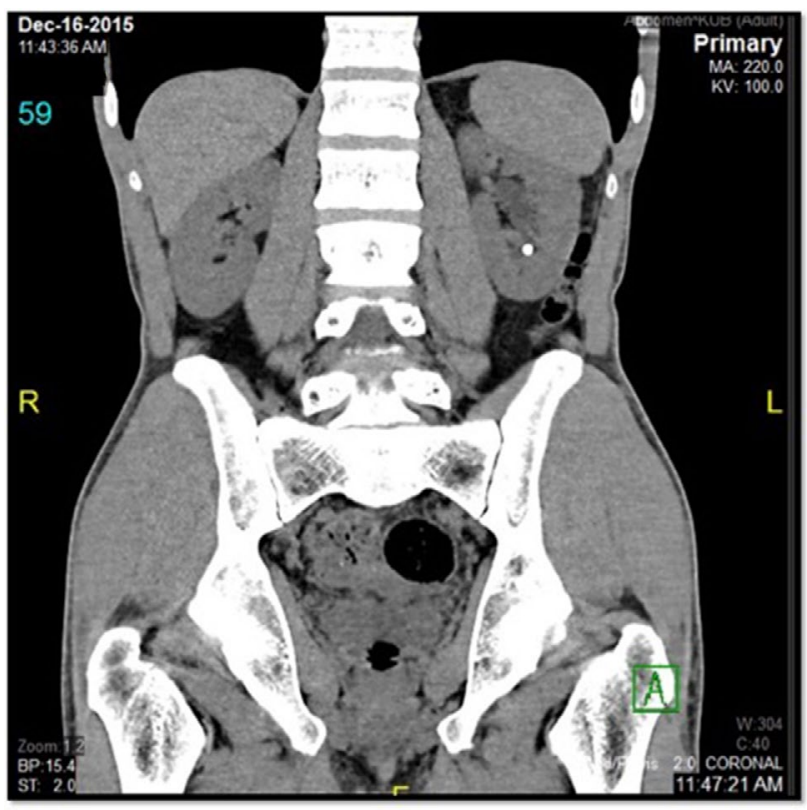

Figure 2 CT-KUB scan showing the upward stone migration to the kidney on December 16, 2015.

Abbreviation: CT-KUB, computerized tomography kidney ureter bladder.

were discussed with the patient and he preferred conservative management. Consequently, he was prescribed alpha blockers and advised to drink plenty of water. The patient was scheduled to be seen again in the clinic after 2 weeks and instructed to return to the emergency department if the pain recurred or if he developed fever or hematuria.

On December 16, 2015, the patient presented to his followup appointment and reported resolution of the painful attacks. Importantly, the patient denied stone passage with urine. He stated that he resumed his regular active lifestyle, including running, jumping over barriers and doing the other habitual military exercises. As the patient had a plan to travel back home on a long-distance flight, CT-KUB scan was performed again to assure he would not have renal colic attacks during his flight. Surprisingly, this scan revealed a small left lower calyx renal calculus with no evidence of ureteric stone (Figure 2).

\section{Discussion}

The prevalence and incidence of urolithiasis are increasing globally. ${ }^{2}$ In one study that was performed among urolithiasis patients from 30 different nationalities living in Saudi Arabia, the prevalence of urinary calculi was found to be higher among Egyptians (29.5\%), immediately followed by Pakistanis (24.9\%). ${ }^{7}$ In another similar study, the highest prevalence percentage was among the Pakistani population. ${ }^{8}$ Moreover, Saudi Arabia is considered as one of the countries with the highest incidence of urolithiasis. ${ }^{3}$ All of this confirms our patient lives in and comes from a place where urolithiasis is quite common.

Urinary tract stone formation is associated with metabolic abnormalities, which may include hypercalciuria, hyperphosphaturia, hyperoxaluria, hypocitraturia, hyperuricosuria, cystinuria, a low urinary volume and a defect in urinary acidification. ${ }^{9}$ Our patient was not affected by any of these conditions.

Furthermore, urolithiasis is also known to be associated with many environmental factors such as the amount of fluid intake, dietary intake of salt, protein, calcium and other nutrients. Additionally, urinary tract infections, socioeconomic status of the individual and patient lifestyle play a role in urolithiasis. ${ }^{10}$

It has been proven that the prevalence of urolithiasis is higher in areas with increased environmental temperatures. ${ }^{2}$ Since the climate in Makkah is usually hot, that could be one of the main causes of urolithiasis in our patient as he works daily under the sunlight for long hours.

The ureteric downward peristalsis enhances the spontaneous passage of $<5 \mathrm{~mm}$ ureteric stones. Stone diameter of $\geq 5 \mathrm{~mm}$ is associated with a progressive decrease in the spontaneous passage rate, ${ }^{11}$ while stones $\geq 10 \mathrm{~mm}$ in diameter are unlikely to pass out spontaneously. Proximal ureteral stones are also less likely to pass spontaneously.

On the initial CT-KUB scan, our patient's stone was in the proximal left ureter. Paradoxically, after that, the stone had migrated spontaneously upward to the renal calyx. This phenomenon has been reported only once in the literature. ${ }^{6}$ It is possible that this situation is not that uncommon, but it is underreported in the literature. The previously reported case referred to the retrograde movement of the lower third ureteric 
stone to the reversed ureteral peristalsis. In addition to that theory, we attributed the upward ureteric stone migration to excessive exercises, given the fact that the ureter proximal to the stone is usually dilated allowing the stone to roll back into the kidney. Other theories could also contribute to this behavior of the ureteric calculi, including the kidney response to obstruction by reducing the glomerular filtration rate, which results in reducing the pressure in the renal pelvis, which also potentially helps the upward stone migration. Moreover, the use of nonsteroidal anti-inflammatory drugs for relieving renal colic reduces the glomerular filtration rate by interrupting the renal pelvis pacemaker cells, thus resulting in reducing the ureteric peristalsis. ${ }^{12}$ This could be a contributing factor in the process of retrograde migration of the ureteric stones, however, the patient denied taking any of these medications.

The patient was informed that data concerning the case would be submitted for publication, and he provided a consent.

\section{Conclusion}

Urolithiasis is a common disease worldwide and is known to be associated with multiple metabolic and environmental factors. Retrograde ureteric stone migration is an underreported phenomenon. It has been reported only once in the literature and attributed to the reversed ureteric peristalsis. ${ }^{6}$ We report the second documented case of this unusual outcome of ureteric stone and provided other theories to explain it. We highly recommend stone localization imaging prior to any intervention, to avoid unnecessary procedures.

\section{Disclosure}

The authors report no conflicts of interest in this work.

\section{References}

1. Soomro HU, Ather MH, Salamb B. Comparison of ureteric stone size, on bone window versus standard soft-tissue window settings, on multi-detector non-contrast computed tomography. Arab JUrol.2016;14(3):198-202.

2. Romero V, Akpinar H, Assimos DG. Kidney stones: a global picture of prevalence, incidence, and associated risk factors. Rev Urol. 2010; 12(2-3):e86-e96.

3. Romello A, Vitale C, Marangella M. Epidemiology of nephrolithiasis. J Nephrol. 2000;13(3):45-50.

4. Kang HW, Lee SK, Kim WT, et al. Natural history of asymptomatic renal stones and prediction of stone related events. J Urol. 2013;189(5): $1740-1746$.

5. Nazim SM, Ather MH, Khan N. Measurement of ureteric stone diameter in different planes on multidetector computed tomography - impact on the clinical decision making. Urology. 2014;83(2):288-293.

6. Khan Z, Yaqoob AA, Bhatty TA. Spontaneous retrograde migration of ureterovesical junction stone to the kidney; first ever reported case in the English literature in human. Urol Ann. 2016;8(2):229-232.

7. Ahmad F, Nada MO, Farid AB, Haleem MA, Razack SM. Epidemiology of urolithiasis with emphasis on ultrasound detection: A retrospective analysis of 5371 cases in Saudi Arabia. Saudi J Kidney Dis Transpl. 2015;26(2):386-391.

8. Buchholz NP, Abbas F, Afzal M, Khan R, Rizvi I, Talati J. The prevalence of silent kidney stones - an ultrasonographic screening study. J Pak Med Assoc. 2003;53(1):24-25.

9. Frick KK, Bushinsky DA. Molecular mechanisms of primary hypercalciuria. J Am Soc Nephrol. 2003;14(4):1082-1095.

10. Curhan GC, Willett WC, Rimm EB, Stampfer MJ. A prospective study of dietary calcium and other nutrients and the risk of symptomatic kidney stones. $N$ Engl J Med. 1993;328(12):833-838.

11. Miller OF, Kane CJ. Time to stone passage for observed ureteral calculi. A guide for patient education. J Urol. 1999;162(3 pt 1):688-690.

12. Davenport K, Waine E. The role of non-steroidal anti-inflammatory drugs in renal colic. Pharma J. 2010;3(5):1304-1310.
Research and Reports in Urology

\section{Publish your work in this journal}

Research and Reports in Urology is an international, peer-reviewed, open access journal publishing original research, reports, editorials, reviews and commentaries on all aspects of adult and pediatric urology in the clinic and laboratory including the following topics: Pathology, pathophysiology of urological disease; Investigation and treatment of

\section{Dovepress}

urological disease; Pharmacology of drugs used for the treatment of urological disease. The manuscript management system is completely online and includes a very quick and fair peer-review system, which is all easy to use. Visit http://www.dovepress.com/testimonials.php to read real quotes from published authors. 